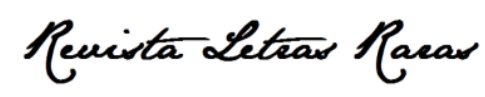

ISSN: 2317-2347 - v. 10, n. 4 (2021)

Todo o conteúdo da RLR está licenciado sob Creative Commons Atribuição 4.0 Internacional

\title{
O devir dos animais não-humanos em um mundo pós-
}

\author{
pandêmico /
}

The becoming of the non-human animals in a post pandemic

\author{
world
}

\section{Sueli Meira Liebig*}

Professora Associada do Departamento de Letras na graduação e da pós-graduação em Literatura e Interculturalidade (MLI/PPGLI) da Universidade Estadual da Paraíba (UEPB). Possui doutorado em Letras/literatura comparada pela UFMG -Universidade Federal de Minas Gerais/UGA -Universidade da Geórgia em Athens, USA (2002).

(iD) https://orcid.org/0000-0002-5549-9510

\section{Rafaela Liebig Ramalho Lucena **}

Rafaela Liebig Ramalho Lucena é graduanda em Direito pela Universidade Federal de Alagoas, onde tem feito pesquisas na área de antropologia e direitos dos animais.

Recebido em: 21 out. 2021. Aprovado em: 20 nov. 2021.

\section{Como citar este ensaio:}

LIEBIG, Sueli Meira. LIEBIG, Rafaela. O devir dos animais não-humanos em um mundo póspandêmico. Revista Letras Raras, Campina Grande, v. 10, n. 4, p. 69-78, dez. 2021.

\section{RESUMO}

O presente trabalho visa a trazer um olhar ecocrítico sobre os animais não-humanos a partir da consideração sobre o seu devir em um contexto pós-pandêmico, com enfoque antiespecista, posto que boa parte da literatura que retrata a relação entre seres humanos e demais espécies o faz sob uma perspectiva instrumental, considerando os interesses humanos e o valor do animal enquanto objeto, a exemplo da preservação dos animais silvestres enquanto elementos componentes da fauna. Aqui será apontado de que maneira as habilidades compartilhadas entre indivíduos humanos e não-humanos confluem para a caracterização dessa personalidade. Assim como o ideal de dignidade humana considerado está necessariamente atrelado ao conceito de mínimo existencial, com o consequente rol de direitos mínimos para sua autopreservação, em um devir pós-pandêmico -paralelamente e guardadas as devidas proporções - faz-se necessário a compreensão dos indivíduos não humanos enquanto - também- sujeitos de direito, com a construção de uma dignidade própria, derivada da dignidade humana, mas que com ela não se confunde.

PALAVRAS-CHAVE: Antiespecismo; Devir animal; Direito animal; Indivíduos não-humanos.

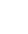

suelibig@hotmail.com

suelibig@gmail.com 


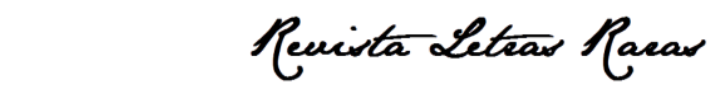

ISSN: 2317-2347 - v. 10, n. 4 (2021)

Todo o conteúdo da RLR está licenciado sob Creative Commons Atribuição 4.0 Internacional

\section{ABSTRACT}

This work aims at bringing an ecocritical look upon the non-human animals taking into consideration their becoming in a post-pandemic world, focusing on anti-speciesism, since most Literature that deal with the relationship between human beings and other species does it under an instrumental perspective, considering human interest and the animal's value while an object, as for example the preservation of wild animals as elements that belong to the fauna. Here will be pointed out the way how the shared abilities between human and non-human individuals conjoin to the characterization of this personality. As well as the considered ideal of human dignity is necessarily linked to the concept of existential minimum and the subsequent list of basic rights for its self-preservation, in a post-pandemic future concurrently and respected the due proportions - it becomes mandatory the comprehension of non-human individuals while equally subjects with rights, with the construction of a proper dignity that as though is derived from human dignity is not interchangeable with it.

KEYWORDS: Anti-speciesism; Animal Becoming; Animal right; Non-human individuals.

\section{Introdução}

A análise e reanálise dos valores existenciais é indispensável para a constante evolução da estrutura social humana. $O$ homem sempre ensaiou a criação de sua própria cultura baseada nos seus sistemas de crenças vigentes e limitações. Em decorrência dessas limitações, a forma como a humanidade construiu e constrói a própria narrativa ético-moral, ao longo da história, sempre se manifestou, de uma forma ou de outra, em exclusões e privilégios.

Grupos foram segregados pela cor da sua pele, por questões de gênero, por características etárias, geográficas, por escolhas religiosas etc. Com essa segregação houve violência e estigmas, todos muito bem justificados a sua época. Muitos argumentam que essa estrutura de exclusão de indivíduos faz parte do jogo natural de poder que estruturou as bases da sociedade e, por isso, além de inevitáveis seriam também necessários e até mesmo desejáveis para garantir a estrutura e desenvolvimento da própria civilização e em última análise da espécie homo sapiens.

Tais justificativas foram a base para falácias naturalistas que legitimaram ao longo do tempo violências e segregação de espaços, alcançando assimetrias inimagináveis para nossa ética atual. Contudo, sendo a ética uma valoração sobre a moral, a qual gera o lastro de valor da própria humanidade, o que a ética moderna diria sobre a estrutura social atual?

A narrativa que tenta unir o homo sapiens em sua dignidade lastreada em valores universais, se dedicada a alcançar a erradicação dos flagelos da humanidade como os abismos sociais, doenças, guerras e fome, muitas vezes é a mesma narrativa que nega a responsabilidade 


\section{Penista Letras Paras}

ISSN: 2317-2347 - v. 10, n. 4 (2021)

Todo o conteúdo da RLR está licenciado sob Creative Commons Atribuição 4.0 Internacional

humana sobre o sofrimento inenarrável de outras espécies, sofrimento este, na grande maioria das vezes, desnecessário. Sobre o tema Yuval Noah Harari expõe que:

Uma vez que os corpos humano e animal eram o único dispositivo de conversão de energia disponível, a energia muscular era essencial para quase todas as atividades humanas. Músculos humanos construíam carroças e casas, músculos de bois aravam campos e músculos de cavalos transportavam alimentos [...]. Infelizmente, a perspectiva evolutiva é um parâmetro de sucesso relativo. Julga tudo segundo os critérios de sobrevivência e reprodução, sem considerar o sofrimento e a felicidade individuais. As galinhas e as vacas domesticadas podem ser uma história de sucesso evolutivo, mas também estão entre as criaturas mais miseráveis que já existiram. A domesticação de animais se baseou em uma série de práticas brutais que só se tornaram cada vez mais cruéis com o passar dos séculos. (HARARI, 2018, p. 345)

Em pleno século XXI, onde a possibilidade de consciência é plena mediante 0 alcance ubíquo da informação, o que nossa autocrítica como espécie nos aponta sobre a atual estrutura fundada no sofrimento dos que carecem de poder? O pensamento ético-moral atual tenta voltarse quase que exclusivamente para problemáticas humanas. No século XXI as minorias ganham visibilidade inevitável perante a história, todavia uma consciência universal de responsabilidade supraespécie é novamente negada por falácias narrativas.

Mais especificamente, no contexto de pandemia, a relação humana com as demais espécies merece atenção redobrada, uma vez que a criação extensiva de animais está diretamente relacionada às grandes catástrofes biológicas experienciadas pela humanidade, como a Varíola, Peste Bubônica, HIV, H1N1, Ebola entre outras, conforme esclarece a obra: Pandemias, saúde global e escolhas pessoais (ALONSO; PAIM, 2020). Na mesma obra os autores instruem:

Tendemos a abordar cada nova epidemia e crise na saúde pública de forma independente, em vez de reconhecer que esses problemas são sintomas de algo comum. Os animais têm servido à humanidade por milênios, mas nas sociedades modernas atuais precisamos ser francos e admitir que a esmagadora maioria dos sistemas de produção animal tidos como ultramodernos, somada a formas ultra-primitivas de obtenção de proteína animal diretamente da biodiversidade representam um risco para a saúde pública altíssimo. A extensão das perdas humanas e financeiras provenientes dos diversos surtos de doenças infecciosas cuja origem se remete a estes sistemas, assim como da resistência a antibióticos, fazem deste um problema social e econômico também. (ALONSO; PAIM, 2020, p. 57-58) 


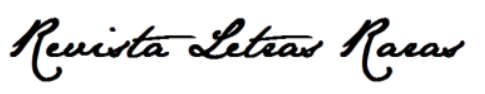

ISSN: 2317-2347 - v. 10, n. 4 (2021)

Todo o conteúdo da RLR está licenciado sob Creative Commons Atribuição 4.0 Internacional

Neste sentido, não há como abordar a temática pandêmica, sem, no entanto, referir-se a uma de suas principais causas: a relação do homo sapiens com as demais espécies. No entanto, conforme pontuado inicialmente, aqui não se encontra uma abordagem biológica dos impactos da exploração animal na saúde humana, neste cenário, utiliza-se a necessidade de questionar as escolhas pessoais e coletivas, provocadas pela pandemia mundial, como um convite para avaliações filosóficas e jurídicas menos antropocêntricas.

\section{Do caráter valorativo da senciência animal}

Por muito tempo se questionou a capacidade de sentir da maioria dos animais, hoje cientificamente incontroversa. Aqui destaco os estudos relativos à senciência animal (ATAÍDE Jr., 2021), área de conhecimento responsável por compreender a capacidade de experiência consciente dos seres, que nos trouxe relevantes descobertas acerca do grau de afetação consciente, tanto positiva quanto negativa, que os indivíduos não-humanos são capazes de experienciar, dentre elas a possibilidade de desenvolvimento de emoções complexas e adoecimento psíquico. Estas descobertas possuem fundamental importância para 0 reconhecimento da dignidade dos animais não humanos, conforme expõe Vicente Ataíde Junior:

A dignidade animal é derivada do fato biológico da senciência, ou seja, da capacidade de sentir dor e experimentar sofrimentos, físicos e/ou psíquicos. A senciência animal é juridicamente valorada, quando posta em confronto com as interações e atividades humanas, pela positivação da regra fundamental do Direito Animal contemporâneo: a proibição das práticas que submetam os animais à crueldade. (ATAIDE J., 2021, p.48-76)

A senciência, enquanto elemento caracterizador da dignidade, tem se mostrado o critério mais adequado, uma vez que, adotada a racionalidade enquanto atributo jurígeno, esta característica alijaria até mesmo indivíduos humanos da proteção de suas dignidades, a exemplo daqueles que, por causas transitórias ou permanentes, possuem uma grande redução de sua capacidade cognitiva.

Neste contexto, considerando que a racionalidade e seus atributos decorrentes como cultura, linguagem, entre outros, constituem a principal diferença entre a espécie humana e as demais, não restaria outro critério capaz de distinguir de maneira adequada os seres que possuem ou não dignidade. Conforme expõe Pedro Henrique Freire, 


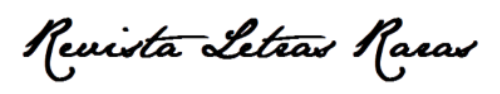

ISSN: 2317-2347 - v. 10, n. 4 (2021)

Todo o conteúdo da RLR está licenciado sob Creative Commons Atribuição 4.0 Internacional

\begin{abstract}
Para além disso, a única característica que distingue todos os seres humanos de todos os animais de outras espécies é a própria espécie. Porém, essa característica é de uma arbitrariedade indefensável e similar a outras, igualmente reprováveis, formas de preconceito. Se todos os seres humanos são possuidores de dignidade e, portanto, de direitos dela decorrentes, como à vida, à liberdade e à integridade física e psíquica, não há justificativa razoável para negar a mesma dignidade para animais não-humanos, iguais a muitos desses humanos em tudo que é moralmente relevante. Qual a possível justificativa para tratar casos similares de maneira diferente? (FREIRE, 2013, p.59-77)
\end{abstract}

Daí surge a necessidade de uma postura ética direcionada a estes indivíduos. Vale lembrar que a senciência é valorada no sistema jurídico brasileiro à medida em que se regula a interação entre indivíduos humanos e não-humanos, com a vedação da prática de atividades cruéis, prevista no Art. 225 §1 VII da Constituição Federal Brasileira- ainda que mitigada pela emenda constitucional $n^{\circ} 96$ ( PEC da vaquejada)- bem como pela lei de crimes ambientais em seu art. 32. Mais recentemente, o artigo fora alterado para ampliar a pena dos crimes cometidos contra cães e gatos.

Importa destacar que, embora positivados, estes dispositivos possuem baixa eficácia enquanto forma de tutelar adequadamente os interesses destes indivíduos e prevenir violações futuras, sobretudo daquelas espécies sobre as quais ainda prevalece a perspectiva civilista clássica que enxerga os animais não-humanos enquanto bens jurídicos análogos aos inanimados, a exemplo dos animais que são tradicionalmente abatidos para alimentação. Noutro passo, é possível também verificar que esta proteção não se dá de maneira homogênea entre as espécies, a exemplo da referida lei 1095/19 que majora a pena dos crimes cometidos contra cães e gatos, ainda que não haja justificadas diferenças entre estas espécies em relação às demais, senão 0 valor culturalmente atribuído àquelas pelos humanos no Brasil.

\title{
3 Dignidade Animal e Dignidade Humana.
}

Não se pode falar sobre a Dignidade animal, sem referenciar aquela atribuída a humanidade, uma vez que, se dignidade humana é um sistema metafísico incondicional de valorização do homem para a sociedade mundial, não a partir de suas habilidades, mas por seu 


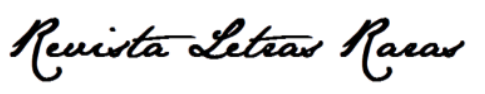

ISSN: 2317-2347 - v. 10, n. 4 (2021)

Todo o conteúdo da RLR está licenciado sob Creative Commons Atribuição 4.0 Internacional

valor moral inerente, logo a dignidade animal surge enquanto desdobramento natural, um reflexo direto dos seus atributos compartilhados, sobretudo a capacidade de experiência consciente.

Assim, a dignidade animal representa uma ampliação ecológica da dignidade humana, fugindo ao padrão antropocêntrico que até o momento se apresenta, ao passo em que se acomoda sob os mesmos pilares.

Immanuel Kant foi um dos principais pensadores a estabelecer os fundamentos do que hoje seria a dignidade humana, não obstante, elenca a racionalidade enquanto requisito essencial à caracterização do status de "pessoa", aqui também compreendido enquanto indivíduo, retirando desta apreciação as demais espécies. Conforme anteriormente exposto, o critério da racionalidade não parece adequado critério a caracterização da dignidade, seja ela humana ou animal, uma vez que não engloba sequer todos os indivíduos humanos Tom Regan (2004), por outro lado, contrapõe e expande a abordagem kantiana, na medida em que desloca a origem jurídica da dignidade, retirando-a da racionalidade, transportando-a para a capacidade de sentir e viver. Isto posto, infere-se que a ética de Regan se baseia nas semelhanças dos humanos e dos animais ao passo que opositores do direito dos animais buscam incessantemente encontrar diferenças. (FREIRE, 2013, 59-77)

\section{Imperativo Ético Abolicionista.}

Reconhecida e valorada a integridade física e psíquica do animal, é comum no campo de discussão da ética e dignidade animal, a apresentação de proposições bem-estaristas que visem a melhorar a qualidade de vida destes animais sem romper necessariamente com os circuitos de instrumentalização das demais espécies. O Bem-estarismo, é uma linha de pensamento do direito animal, cujo elemento central é a promoção do bem-estar e redução do sofrimento destes indivíduos. Neste panorama, admite-se a utilização destas espécies para consumo, entretenimento, vestuário, transporte entre outros fins, desde que sejam estabelecidos e cumpridos parâmetros mínimos de bem-estar e conforto a estes animais.

Para ilustrar esta corrente, temos no âmbito nacional, a PEC da vaquejada (50/2016), que contrapôs a interpretação proibitiva do Supremo Tribunal Federal quanto à prática da vaquejada, entendendo que tais eventos configurariam práticas cruéis vedadas na carta magna em seu artigo 225. Assim, o texto da emenda se apresenta da seguinte forma: 


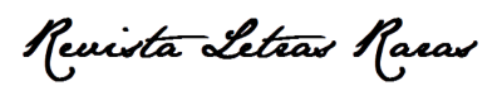

ISSN: 2317-2347 - v. 10, n. 4 (2021)

Todo o conteúdo da RLR está licenciado sob Creative Commons Atribuição 4.0 Internacional

$\S 7^{\circ}$ Para fins do disposto na parte final do inciso VII do $\S 1^{\circ}$ deste artigo, não se consideram cruéis as práticas desportivas que utilizem animais, desde que sejam manifestações culturais, conforme $0 \S 1^{\circ}$ do art. 215 desta Constituição Federal, registradas como bem de natureza imaterial integrante do patrimônio cultural brasileiro, devendo ser regulamentadas por lei específica que assegure o bem-estar dos animais envolvidos (grifo nosso).

Nesse cenário, é perceptível que esta vertente legitima a utilização destes animais para fins de entretenimento, desde que salvaguardados alguns parâmetros legais de bem-estar animal. Esta corrente recebe bastante críticas, sobretudo pela parcela abolicionista, tanto pela baixa efetividade das propostas em melhorar a qualidade de vida dos animais (em razão da falta de fiscalização e garantia das certificações) como por perpetuar os circuitos de exploração animal.

A corrente abolicionista, por outro lado, trata a vida dos animais não-humanos enquanto valor intransigível "Os abolicionistas defendem direitos fundamentais para sujeitos-de-uma-vida: à vida; à liberdade física e psíquica (à sexualidade, à busca do bem próprio sem manejo ou restrição, à não escravização)" ( FELIPE, 2017, online)

Não obstante as divergências entre as duas teorias, é possível em determinado caso concreto que ativistas abolicionistas e bem-estaristas acatem uma mesma proposição que implique em melhorias para o bem-estar animal. Ocorre que para estes restaria cumprido o seu objetivo fim, ao passo em que para aqueles esta solução seria apenas uma etapa meio. Nas palavras de Sônia Felipe ,

A abolição não negocia em parcelas a restituição do bem extorquido dos animais, nem adota a ideia de reduzir os maus-tratos ou diminuir o âmbito no qual eles são infligidos aos animais (bem-estarismo). Abolir é pôr fim à prática completa, desconstruir seus andaimes e retirar os sustentáculos morais que a amparam há milênios. Abolir é extinguir pela raiz a crença na legitimidade moral da exploração e matança de animais pelos humanos para comilança, tração, embelezamento, diversão, tratamento, higiene e atendimento a quaisquer outros propósitos. (FELIPE, 2017, n.p.)

Sob a perspectiva kantiana, o valor atribuído à vida humana lhe confere dignidade no sentido de constituir o indivíduo enquanto um fim em si mesmo. Assim, não se admite a instrumentalização do humano para fins diversos do seu éthos. Analogamente, não se pode mitigar a dignidade animal, ainda que esta instrumentalização- seja para fins de entretenimento, transporte, alimento entre outros- não implique necessariamente em sofrimento físico ou psíquico ao animal. Nesse sentido, o mero desvio do valor inerente à vida dos animais não humanos com 


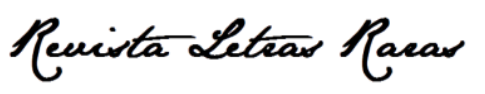

ISSN: 2317-2347 - v. 10, n. 4 (2021)

Todo o conteúdo da RLR está licenciado sob Creative Commons Atribuição 4.0 Internacional

o objetivo de atender às necessidades e interesses humanos, constituiria uma violação ética à dignidade animal.

Como forma de ilustrar este pensamento, transporto um evento e precedente jurídico da experiência humana, no qual a prefeitura da cidade francesa de Morsang-sur-Orge interditou uma casa noturna que promovia um evento de "arremesso de anões" com a utilização de canhões, sob o fundamento de que aquele espetáculo seria atentatório à dignidade da pessoa humana e consequentemente à ordem pública (VALE, 2015). Não restou comprovado neste caso dano psíquico ou físico à pessoa arremessada, em sentido contrário, o senhor Wackenheim pleiteou a revogação da proibição, argumentando que estaria gozando de sua autonomia individual para 0 exercício da atividade.

Neste contexto, infere-se que, considerando que a dignidade, tanto humana quanto animal, constituísse bem jurídico disponível - 0 que não compõe o objeto da presente discussãoainda assim esta hipótese não poderia ser admitida para indivíduos não-humanos, uma vez que faltaria um dos requisitos essenciais para a caracterização desta disponibilidade, qual seja: a faculdade de consentir.

Portanto, à luz da dignidade animal ora perseguida, as alternativas bem-estaristas, embora representem uma evolução em relação à completa indiferença com a qual a sociedade humana trata as demais espécies, não parecem a solução ética mais adequada. Posto que, embora vise melhorar a qualidade de vida destes indivíduos, perpetua o cerne da problemática, a medida em que não reconhece as demais espécies em sua subjetividade, cujos direitos são inerentes, indisponíveis e oponíveis a terceiros.

\section{Conclusão}

O reconhecimento formal da individualidade dos animais não humanos é essencial para a construção de um sistema de proteção sofisticado e eficaz. Uma vez que não é possível atribuir direitos ou interesses a objetos, pois são características típicas dos sujeitos, tal qual a dignidade. No mesmo sentido, a dignidade animal reconhecida está necessariamente atrelada à necessidade de tê-la respeitada, conforme bem explica Ataíde Júnior:

Como toda dignidade deve ser protegida por direitos fundamentais, não se podendo conceber dignidade sem um catálogo mínimo desses direitos, então 


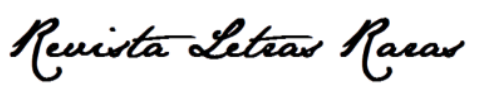

ISSN: 2317-2347 - v. 10, n. 4 (2021)

Todo o conteúdo da RLR está licenciado sob Creative Commons Atribuição 4.0 Internacional

a dignidade animal deve ser entendida como a base axiológica de direitos fundamentais animais, os quais constituem 0 objeto do Direito Animal. (ATAÍDE JUNIOR, 2018, p 48-76)

Considerando que os direitos podem ser também compreendidos enquanto tutela de interesses, se justificou por muito tempo, sob uma perspectiva clássica, que os interesses envolvidos na proteção animal seriam humanos, a exemplo do direito ambiental coletivo de preservação da fauna. No entanto, com o avanço das normas essencialmente animalistas, que protegem o bem-estar e integridade do animal, sob a perspectiva de seus interesses próprios, esta fundamentação tem perdido espaço.

Para ter direitos, é preciso ser alguém, tecnicamente um sujeito de direitos. O que se observa de maneira incongruente no sistema jurídico brasileiro é a bivalência animal representada. Ora o código civil se refere às demais espécies enquanto bens jurídicos e, portanto objetos, ora os percebem enquanto sujeitos, ainda que de maneira não expressa, quando considera seus interesses particulares, vedando a prática de atos cruéis em seu desfavor.

Ocorre que 0 direito, enquanto ciência profundamente marcada por valores e costumes sociais, reproduz a mesma incongruência socialmente observada em relação as demais espécies, que reconhece parcialmente estes direitos ao passo em que se desobriga a respeitá-los. 0 animal passa então a ser considerado um "sujeito-coisa", cujos direitos de sujeito são elencados, sem perder necessariamente o status de coisa e suas características servis.

Em que pese a existência do projeto de lei $n^{0} 27 / 2018$, que atribui a personalidade jurídica aos indivíduos não humanos, passando a desconsiderá-los enquanto objeto, esta consideração deve encontrar forte resistência social. Não pela ausência de assimilação social do animal enquanto sujeito, mas pelas mudanças dela decorrentes.

Portanto é necessário não apenas reconhecer a existência desta subjetividade, como também respeitar os direitos dela decorrentes refutando qualquer utilização dos animais aos interesses humanos. Nesse sentido, se outrora a instrumentalização dos animais fora necessária para a evolução biológica da humanidade enquanto espécie, hoje torna-se incompatível com esta.

Para tanto é essencial o alinhamento dos interesses humanos de preservação ambiental, da saúde global e consistência ética, em relação aos interesses das demais espécies, como de autopreservação, passando necessariamente pelo reconhecimento das suas individualidades. Este será o devir animal em um mundo pós-pandêmico. 


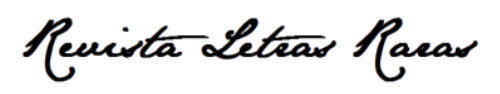

ISSN: 2317-2347 - v. 10, n. 4 (2021)

Todo o conteúdo da RLR está licenciado sob Creative Commons Atribuição 4.0 Internacional

\section{CRediT}

Reconhecimentos: Não é aplicável.

Financiamento: CAPES - Código de Financiamento 001

Conflitos de interesse: Os autores certificam que não têm interesse comercial ou associativo que represente um conflito de interesses em relação ao manuscrito.

Aprovação ética: Não é aplicável

Contribuições dos autores:

Conceitualização, Aquisição de financiamento, Investigação, Metodologia, Administração do projeto, Supervisão, Escrita - rascunho original, Escrita - revisão e edição: LIEBIG, Sueli Meira.

Conceitualização, Aquisição de financiamento, Investigação, Metodologia, Administração do projeto, Supervisão, Escrita - rascunho original, Escrita - revisão e edição: LIEBIG, Rafaela.

\section{Referências}

ALONSO, W.J.; PAIM, C. S. Pandemias, saúde global e escolhas pessoais. Alfenas - MG : Editora Cria, pg. 57-58, 2020.

ATAIDE JUNIOR, V. P. Introdução ao direito animal brasileiro. Revista Brasileira de Direito Animal, Salvador, v. 13, n. 03, p. 48-76, 2018. DOI 2317-4552. Disponível em: https://periodicos.ufba.br. Acesso em: 4 ago. 2021.

BRASIL. [Constituição (1988)]. Constituição da República Federativa do Brasil de 1988. Brasília, DF: Presidência da República, [2021]. Disponível em: http://www.planalto.gov.br/ccivil_03/constituicao/constituicao.htm Acesso em:28/07/2021.

FELIPE, S. T. Por uma questão de princípios. Alcance da ética de Peter Singer em defesa dos animais. Florianópolis: Fundação Boiteux, 2003.

FELIPE, S. T. bolicionismo: Ética E Fundamentação Dos Direitos Animais. Coluna da Associação nacional de pós-graduação em filosofia (ANPOF), [s. I.], 16 ago. 2017. Disponível em: http://anpof.org/portal/index.php/en/comunidade/coluna-anpof/1244-abolicionismo-etica-efundamentacao-dos-direitos-animais. Acesso em: 6 ago. 2021.

FREIRE, P. H. S. G. Dignidade humana e Dignidade animal. Revista Brasileira de Direito Animal, [s. I.], ano 07, v. 11, p. 59-77, 2 ago. 2013. DOI https://doi.org/10.9771/rbda.v7i11.8416. Disponível em: https://periodicos.ufba.br/index.php/RBDA/article/view/8416/0. Acesso em: 30 jul. 2021.

HARARI, Y. N. Sapiens: Uma breve história da humanidade. Porto Alegre: L\&PM Editores S. A. pg $345,2018$.

REGAN, T. The Case For Animal Rights. 2nded. Berkeley: University of California Press, 2004. p. 235-250.

VALE, I. P. "O caso do peep-show e do lançamento de anões em face do princípio da dignidade da pessoa humana: julgados do Tribunal Constitucional" (2015) Disponível em: $<$ https://ioniltonpereira.jusbrasil.com.br/artigos/177516227/o-caso-do-peep-show-e-dolancamento-de-anoes-em-face-do-principio-da-dignidade-da-pessoa-humana-julgados-dotribunal-constitucional>. Acesso em : 01 ago 2021. 